\title{
EVENTO ESPORTIVO OU EXPERIÊNCIA PARA O CONSUMIDOR? UM ESTUDO SOBRE A MOTIVAÇÃO DO CONSUMIDOR EM COMPARECER A EVENTOS DE CORRIDA DE RUA
}

Objetivo: O objetivo desse estudo é identificar os fatores motivacionais que levam os corredores a escolher participar de eventos de corrida de rua.

Método: Para responder ao objetivo foi desenvolvida uma pesquisa quantitativa de caráter descritivo. Elaborou-se um questionário capaz de responder ao objetivo desse trabalho. O questionário continha afirmações correspondentes a nove domínios, onde o indivíduo assinalava o grau de concordância com cada afirmação. A amostra foi composta por 243 corredores.

Originalidade/Relevância: Esse estudo poderá contribuir com os produtores de corrida de rua no momento da elaboração dos eventos, pois, entendendo as motivações de seus consumidores, poderão oferecer um serviço que atenda às expectativas do público desse esporte e, consequentemente, agregue valor à prova.

Resultados: A dimensão que mais motiva os participantes é o condicionamento físico $(4,71)$, seguido pelo excitamento $(4,44)$ e o domínio de habilidades $(4,40)$. A dimensão competição aparece na oitava posição $(3,63)$. Negócios $(3,01)$ foi avaliada como a dimensão que menos motiva os participantes a escolher o evento corrida de rua.

Contribuições teóricas/metodológicas: a motivação desses consumidores e, sim, vários outros aspectos que comtemplem os fatores que interferem na participação dentro do mercado de corrida de rua.

Contribuições sociais / para a gestão: Esse estudo pode auxiliar no entendimento de um componente específico do comportamento do consumidor: a motivação. Além disso, o estudo reforça a ideia da busca do consumidor pelo entretenimento aliado a prática de atividade física.

Palavras-chave: Marketing Esportivo. Comportamento do Consumidor. Eventos Esportivos. Corrida de Rua.

\section{SPORTS EVENT OR CONSUMER EXPERIENCE? A STUDY ON CONSUMER MOTIVATION TO ATTEND STREET RACING EVENTS}

Objective: The aim of this study is to identify the motivational factors that lead runners to choose to participate in street racing events.

Methods: In order to respond to the objective, a descriptive quantitative research was developed. A questionnaire was elaborated to answer the objective of this work. The questionnaire contained statements corresponding to nine domains, where the individual indicated the degree of agreement with each statement. The sample consisted of 243 runners.

Originality / Relevance: This study may contribute to the producers of street racing at the time of the events, because, understanding the motivations of their consumers, they can offer a service that meets the expectations of the public of this sport and, consequently, adds value to the proof.

Results: The dimension that most motivates the participants is the physical conditioning (4.71), followed by the excitement (4.44) and the skill domain (4.40). The competition dimension appears in the eighth position (3.63). Business (3.01) was rated as the dimension that least motivates participants to choose the street racing event.

Theoretical / methodological contributions: the motivation of these consumers and, yes, several other aspects that contemplate the factors that interfere in the participation in the street racing market.

Social / management contributions: This study may help in understanding a specific component of consumer behavior: motivation. In addition, the study reinforces the idea of consumer search for entertainment combined with the practice of physical activity

Keywords: Sports Marketing. Consumer Behavior. Sporting Events. Street Racing.

Pedro Lucas Leite Parolini ${ }^{1}$ Ary José Rocco Júnior ${ }^{2}$ Eduardo De Oliveira Cruz Carlassara ${ }^{3}$

\footnotetext{
1 Mestre em Educação Física pela Universidade de São Paulo - USP. São Paulo, Brasil. E-mail: pedroparolini89@gmail.com

${ }^{2}$ Doutor em Comunicação e Semiótica pela Pontifícia Universidade Católica de São Paulo - PUC/SP. Professor da Escola de Educação Física e Esporte da Universidade de São Paulo - EEFE/USP. São Paulo, Brasil. E-mail: aryrocco@usp.br

3 Mestre em Educação Física pela Universidade de São Paulo - USP. São Paulo, Brasil. E-mail: eoc.carlassara@gmail.com
} 


\section{INTRODUÇÃO}

Um fenômeno esportivo vem chamando a atenção, recentemente, no Brasil. Nas grandes cidades, em qualquer horário, sempre que você passa em um lugar propício para a prática da corrida de rua, você se depara com uma ou mais pessoas correndo. Na verdade, esse fenômeno está se tornando cada vez mais comum. São as pessoas que estão adotando a corrida de rua como um estilo de vida e, independente do horário, clima e local, sempre arrumam uma maneira de praticar a modalidade.

Esse crescimento do número de praticantes de corrida de rua pode ser explicado por alguns aspectos peculiares dessa atividade, como: alta acessibilidade à população apta, baixo custo para o treinamento e benefícios para saúde (Weineck, 2003). Para quantificar esse crescimento, em 2011, a Delloite fez uma pesquisa e identificou que a corrida de rua é, hoje, o segundo esporte mais praticado no país, tanto entre amadores, quanto entre profissionais, perdendo apenas para o futebol (Delloite, 2011).

Paralelamente, a adesão a eventos de corrida de rua também vem aumentando nos últimos anos, fato comprovado pelo crescimento desde 2004 (FPA, 2016). Nos últimos anos, entre 2004 e 2015, somente no estado de São Paulo, o número de participantes em eventos de corrida de rua cresceu de 146 mil corredores para 724 mil, totalizando um aumento de $500 \%$ nesse período (FPA, 2016). Concomitante a esse aumento do número de participantes em eventos de corrida de rua está o crescimento do número de provas ofertadas em todo Brasil, em especial, no estado de São Paulo. Segundo a FPA - Federação Paulista de Atletismo (2015), o número de provas de Corrida de Rua nos últimos anos cresceu cerca de $282 \%$, aumentando de 147 provas, em 2004, para 415, em 2015.

Van Bottenburg, Hover e Scheerder (2010) creditam esse crescimento da prática de corrida de rua como sendo o segundo running boom, iniciado no final dos anos 1990. Comparado com o primeiro boom (década de 1970), este vem com maior participação de homens e mulheres de meia idade. Ainda, segundo os autores, enquanto no primeiro boom o caráter competitivo prevalecia, neste segundo momento, os corredores optam por correr pelo condicionamento físico, hobby e alívio de stress.

Nesse sentido as corridas de rua podem ser vistas sob três dimensões do esporte, segundo proposta feita por Tubino (2002): educação, lazer e competição. Nos dias atuais, o caráter competitivo dessa modalidade está sendo deixado para segundo plano, em detrimento de um perfil de participante desse tipo de evento, mais voltado para a participação e entretenimento (Maioral, 2014). Ainda segundo o autor, e para ilustrar esse fato, mais de $60 \%$ dos corredores europeus têm entre 30 e 55 anos, são pais de família e apontam a flexibilidade para praticar esse esporte como um fator determinante em relação a outras modalidades.

Um dos aspectos que mais contribui para a grande procura de pessoas pela prática amadora desse esporte é o discurso de "superação pessoal" (Gomes, 2012). Outro aspecto importante, esse mais recente, é a chamada "disputa de corpos e dados nas redes sociais", mostrando o poder do ciberespaço nesse ambiente (Maioral, 2014).

Partindo desse pressuposto, Rocco Júnior (2006) acredita que esse ambiente, o das redes sociais, propicia a interação e o diálogo. Ainda, segundo o autor, o ciberespaço não substitui o mundo real, no entanto, reforça a ideia de interação e pertencimento do sujeito. É o local ideal para compartilhamento de informações entre corredores, como fotos, vídeos, medalhas, superação em treinos e provas, reforçando, diariamente, o sentimento de pertencer a algo ou a algum grupo social.

Como observado, o crescimento do mercado de corrida de rua é evidente e o estado de São Paulo não foge à regra. É possível perceber que esse crescimento se deve muito ao aumento da prática amadora da modalidade e pelos motivos que os participantes escolhem correr e participar de eventos de corrida de rua (Gomes, 2012). Diante disso, o objetivo desse estudo é identificar os fatores motivacionais que levam os corredores a escolher participar de eventos de corrida de rua. Esses dados podem se tornar fundamentais nas decisões estratégicas dos gestores e produtores de eventos da modalidade. Para delimitar melhor nosso estudo, escolhemos trabalhar especificamente com o evento Maratona de São Paulo.

A Maratona de São Paulo foi escolhida para o escopo desse estudo por ser o segundo maior evento de corrida de rua do estado de São Paulo, atrás apenas da tradicional corrida de São Silvestre, realizada no último dia do ano. Porém, a São Silvestre traz, ao lado de corredores profissionais e amadores, um número grande de participantes que apresenta, como objetivo único de sua participação, a festa, o entretenimento, a confraternização. Foge, com isso, da proposta deste estudo. Daí a opção, para realização desta pesquisa, pelo evento Maratona de São Paulo.

Este estudo propiciará aos gestores e produtores de eventos de corrida de rua um maior entendimento do comportamento dos seus 
consumidores, no caso os corredores, além de auxiliar pesquisas futuras sobre as motivações que levam os indivíduos a praticarem e escolherem eventos da modalidade. Essa identificação dos fatores motivacionais poderá contribuir com os produtores de corrida de rua no momento da elaboração dos eventos, pois, entendendo as motivações de seus consumidores, poderão oferecer um serviço que atenda às expectativas do público desse esporte e, consequentemente, agregue valor à prova.

\section{Corrida de Rua e seu mercado}

Apesar das antigas manifestações do ato de correr e do fato do atletismo ter sido desenvolvido na Inglaterra, os autores, em geral, concordam que o marco inicial para a corrida de rua aconteceu em 1896, nos Jogos Olímpicos de Atenas, na Grécia (Maioral, 2014). A prova teve a metragem de 40 quilômetros e homenageava o mensageiro Phidippides, que percorreu distância semelhante entre as cidades de Maratona e Atenas, na Grécia Antiga, para entregar a mensagem da vitória dos gregos em uma guerra. Logo após completar sua missão, Phidippides faleceu. Essa é a principal versão para o surgimento da maratona (Dallari, 2009).

Em relação à chegada desse esporte no Brasil, existem algumas suposições. A mais conhecida é a de que a primeira corrida de rua aconteceu em 1912 e foi denominada de "O Estadinho", pois fora organizada, muito embora realizada no Rio de Janeiro, pelo jornal Estado de São Paulo (Webrun, 2002). Outra versão é a de que a primeira corrida no país foi realizada na Bahia, no ano de 1906 (Maioral, 2014).

De acordo com a CBAt - Confederação Brasileira de Atletismo, as provas da modalidade no início do século XX tinham enorme prestígio, sendo tão importantes quanto as provas de regatas. Ainda segundo a CBAt, a maior prova do Brasil, a Corrida de São Silvestre, teve sua primeira edição em 1925 , com 60 atletas. No ano de 2013, a corrida contou com 22 mil participantes (Globoesporte, 2015). Esse aumento do número de participantes da São Silvestre e de outras corridas pelo Mundo, segundo Noakes (1991), deve-se a Kennedy Cooper, médico norte-americano que, em 1968, escreveu um livro sobre os benefícios da prática da corrida de rua, resultando no primeiro running boom, na década de 1970.

A tradicional Corrida de São Silvestre é apenas uma das 361 provas que aconteceram no estado de São Paulo, durante o ano de 2014. Esse número representa um crescimento de $11,63 \%$ em relação a 2013, contando apenas com as provas chanceladas pela Federação Paulista de Atletismo.
Quando incluímos as corridas sem alvará, esse número chega a 598, contra 502 do ano anterior (FPA, 2016).

Todas essas corridas de rua que aconteceram em 2014 no estado de São Paulo e em todo o Brasil, além de proporcionar momentos de lazer e saúde, contribuíram para o desenvolvimento da economia do setor. No ano de 2013, as receitas oriundas desse tipo de evento esportivo chegaram perto dos R\$ 4 bilhões (Diário Catarinens, 2013). Isso demonstra o quanto a corrida de rua está sendo vista como um negócio nos dias atuais. Entre os stakeholders envolvidos nesse setor, podemos citar três grandes agentes: instituições que organizam as corridas de rua; empresas parceiras; organizações e profissionais satélites (Campos, Moraes \& Lima 2014). Essa relação entre os agentes pode ser visualizada na figura 1 .

Entre os três grandes agentes desse modelo proposto por Campos et al. (2014), as instituições organizadoras de corrida têm como papel nesse sistema produzir e promover os eventos de corrida de rua, enquanto as empresas parceiras são organizações interessadas em associar sua marca ao evento, caracterizando o patrocínio esportivo (Maioral, 2014). Os profissionais e instituições satélites são agentes que atendem aos praticantes de corrida de rua, como por exemplo, médicos, nutricionistas, fisioterapeutas, academias e lojas de roupas, entre outras. Oliveira (2010) acredita que o aumento do número de praticantes fez surgir, recentemente, alguns novos stakeholders nesse mercado, como as revistas especializadas em corrida de rua e as assessorias esportivas.

Diante desse contexto cada vez mais complexo, como não pensar a corrida de rua como um produto? Oliveira (2010) dividiu esse tipo de evento em dois subprodutos, chamando-os de corridas convencionais e corridas fashions . O primeiro subproduto, as corridas convencionais, são aquelas que estão vinculadas aos valores tradicionais da corrida de rua. Os corredores participantes são, geralmente, profissionais e indivíduos de classes sociais mais baixas. Oliveira (2010) em sua pesquisa verificou que os participantes dessas provas se dizem "corredores de verdade". O segundo subproduto, as corridas fashions, são corridas com valor de inscrição mais alto e que, consequentemente, atraem um público de poder aquisitivo mais elevado e, em geral, mais exigente. Com isso, tais eventos demandam de seus organizadores uma produção mais elaborada. Nessas corridas, os atletas profissionais são convidados, porém, sua participação não chega a 1 $\%$ do total de inscritos (Oliveira, 2010).

A Maratona de São Paulo carrega alguns dos elementos das corridas fashions citados por Oliveira (2010), como: alto valor de inscrição, 
produção mais elaborada e maior número de corredores amadores do que profissionais. Os corredores amadores que participam da Maratona de São Paulo são os agentes que iremos chamar de consumidores desse esporte. Em razão disso, é necessário o entendimento desse público, pois, são agentes considerados fundamentais para o mercado running, consumindo produtos e serviços oferecidos por empresas desse segmento, fazendo com que o sistema se mantenha ativo e em alta. Para que a demanda de clientes para os produtos e serviços oferecidos continue crescendo, é preciso que os organizadores ofereçam um produto que satisfaça o consumidor. Para o produto satisfazer o consumidor, é imprescindível, antes de tudo, que suas necessidades sejam entendidas. É esse o ponto central deste trabalho: entender o comportamento do consumidor do mercado de corrida de rua.

Inicialmente, precisamos conceituar o corredor. Na literatura, existem várias definições, diversos parâmetros para definir o corredor de rua. Segundo a NSGA - National Sporting Goods Association $^{4}$, os corredores são definidos pela frequência da prática. Dallari (2009) considera como corredor, o indivíduo que, no mínimo, três vezes por semana pratica a modalidade ao ar livre e que pretende participar de competições de corrida de rua. No caso deste artigo, optamos pela definição de Maioral (2014), que define corredor como aquele que participou de um evento de corrida de rua nos últimos 12 meses.

Agora que escolhemos qual definição de corredor melhor se encaixa neste trabalho, é necessário entender com mais profundidade o comportamento desse grupo. Qual o perfil desse público? Quais são as principais motivações que os levam a participar de um evento de corrida de rua? Esta última, tema central deste estudo, é o que pretendemos compreender de forma mais clara ao final da pesquisa. Nesse artigo o corredor é considerado um consumidor dos eventos de corrida de rua, uma vez que esse passa por um processo de tomada de decisão de comparecer ou não a esses eventos, o consome, e posteriormente analisa o custo-benefício dessa participação. Para isso é necessário o entendimento desse comportamento do consumidor de eventos esportivos.

\section{Comportamento do Consumidor Esportivo}

Funk (2008) define o comportamento do consumidor de eventos esportivos como o momento de satisfazer suas necessidades e desejos por meio do seguinte processo: selecionar, comprar, usar e descartar produtos e serviços relacionados com o evento em questão.
Esse comportamento pode se alterar de consumidor para consumidor, dependendo do seu grau de interesse e envolvimento com determinada modalidade. Esse consumo, segundo Funk (2008), pode ainda afetar consumos de produtos e serviços de outras áreas, como roupas, alimentação, filmes, todos com alguma ligação com essa prática esportiva. Nenhum consumidor é igual. Por exemplo, dependendo da sua ligação com o clube, atleta ou até mesmo região, alguns torcedores vão a jogos diariamente, enquanto outros vão ocasionalmente. Um determinado número de consumidores está disposto a gastar certa quantia em produtos associados àquele esporte, ao contrário de outros consumidores (Redden e Steiner 2000). Além disso, esse envolvimento pode ser em maior ou em menor grau, dependendo da época e da performance da equipe ou atleta (Stewart, Smith \& Nicholson, 2003).

Ainda nessa linha, Holbrook e Hirschman (1982) afirmam que o comportamento do consumidor é algo complexo de mensurar, pois, envolve uma interação entre os organismos e o meio ambiente. Os autores reforçam ainda a questão da experiência (sentimentos, diversão, fantasia) como um dos fatores para delimitar esse comportamento do consumidor. Sugere-se então que as pesquisas nessa área devem ir além de simplesmente estudar o perfil do consumidor sua forma de consumo, e sim acrescentar aspectos hedônicos e sentimentos envolvidos nas diversas formas de consumo de um produto ou serviço. Neste estudo, usaremos como fundamentação teórica a abordagem multidimensional do comportamento do consumidor esportivo, na qual se acredita que o comportamento do consumidor pode ser estudado sobre uma ampla gama de motivações e crenças (Stewart et al., 2003). Essas motivações e crenças são agrupadas em torno dos seguintes fatores: motivações primárias; fator emocional; fator econômico; identificação; lealdade; foco conectivo; experiência; participação em jogo. A abordagem multidimensional fornece uma descrição mais rica desse comportamento do consumidor (Stewart et al., 2003). Para melhor entendimento, esses oito fatores podem ser visualizados no quadro 1, juntamente com os comportamentos associados a cada um deles.

\footnotetext{
${ }^{4}$ NSGA-Associação Nacional de "Produtos Esportivos"
} 


\begin{tabular}{|c|c|}
\hline Tipo do fator & Comportamentos \\
\hline Motivações primárias & $\begin{array}{l}\text { Escapar do stress } \\
\text { Excitação e divertimento no evento } \\
\text { Interação Social }\end{array}$ \\
\hline Fator emocional & $\begin{array}{l}\text { Apego Obsessivo e forte comprometimento } \\
\text { Apego moderado e compromisso condicional } \\
\text { Apego Leve e comprometimento frágil }\end{array}$ \\
\hline Fator Econômico & $\begin{array}{l}\text { Alto valor de comprometimento financeiro } \\
\text { Médio valor de comprometimento financeiro } \\
\text { Baixo valor de comprometimento financeiro }\end{array}$ \\
\hline Identificação & $\begin{array}{l}\text { Time usado para confirmar autoconceito } \\
\text { Time usado para confirmar orgulho da comunidade } \\
\text { Time usado para confirmar identificação cultural }\end{array}$ \\
\hline Lealdade & $\begin{array}{l}\text { Lealdade por meio da participação de jogos } \\
\text { Lealdade por meio do uso de cores do time } \\
\text { Lealdade por meio de conversa e chat sobre o time }\end{array}$ \\
\hline Foco Conectivo & $\begin{array}{l}\text { Equipe é a principal conexão do indivíduo } \\
\text { Esporte ou a liga é a principal conexão } \\
\text { O atleta é a conexão principal com a modalidade }\end{array}$ \\
\hline Experiência & $\begin{array}{l}\text { Racional ( Análise Estratégica) } \\
\text { Simbólica (Gestos, cerimônias e rituais) } \\
\text { Social ( integração em jogos e socialmente) }\end{array}$ \\
\hline Participação em jogo & $\begin{array}{l}\text { Frequente } \\
\text { Moderado } \\
\text { Baixa }\end{array}$ \\
\hline
\end{tabular}

\section{Quadro 1 - Abordagem Multidimensional do Comportamento do Consumidor STEWART, SMITH E NICHOLSON}

Fonte: Stewart, B; Smith, A; Nicholson, M .(2003)

Mullin, Hardy e Sutton (2004) acreditam que existem fatores que influenciam o consumidor do esporte e podem ser divididos em fatores intrínsecos ou individuais e fatores extrínsecos ou ambientais. Para os autores, dentro dos fatores individuais, podemos citar a autoimagem, características físicas, aprendizagem, percepção e motivação. Entre os fatores ambientais, incluímos valores culturais, classe, grupos de referência (pessoas significativas), gênero, condições climáticas e geográficas, comportamento de mercado das empresas esportivas e estrutura de oportunidade esportiva (Mullin, Hardy \& Sutton, 2004).

Como esse estudo foca nas motivações que levam os corredores a escolherem o evento Maratona de São Paulo, focaremos mais nesse aspecto da influência no comportamento do consumidor.

Se seguirmos a teoria da motivação, existem estímulos ambientais que, de certa forma, ativariam impulsos de satisfazer uma necessidade subjacente (Mullin et al., 2004). Existem alguns fatores dentro do campo da motivação que influenciam o envolvimento esportivo. Entre eles, os mais relevantes são a conquista ou a noção de vencer; a arte ou o aprendizado de uma nova habilidade; comunidade ou o sentimento de socialização; saúde e boa forma física e diversão e festividades (Mullin et al., 2004).

Quando falamos em motivação para participar de eventos esportivos, tema central deste estudo, Maioral (2014) acredita que para que os organizadores desses eventos possam ter retorno positivo dos participantes, eles devem entender seu comportamento, ou seja, como é seu processo de tomada de decisão de participar ou não do evento. Nesse processo de decisão, Hawkins, Mothersbaugh, David \& Best (2007) desenvolveram cinco etapas para melhor entendimento dessa escolha. São elas: (1) problema do reconhecimento da necessidade: o consumidor tem um desejo ou necessidade que deve ser correspondido; (2) busca da informação: o consumidor busca informações internas (memórias passadas) e externas para decidir; (3) avaliação das alternativas: o consumidor analisa as informações recolhidas na etapa 2, para melhor escolha; (4) seleção e participação: o consumidor decide, considerando as opções que possui, de qual evento irá participar; (5) avaliação pós-participativa: o consumidor avalia sua participação de acordo com a expectativa gerada. Se a percepção positiva for menor que a expectativa, ele está insatisfeito. Caso a percepção positiva for maior que a expectativa ele está satisfeito. Todas essas informações são extremamente valiosas aos produtores de eventos 
esportivos. De posse delas, é possível ter um maior entendimento do seu consumidor e, consequentemente, promover eventos que satisfaçam aos anseios dos seus clientes.

Indo ao encontro, Palhares et al (2012) identificam que as principais motivações para a prática da corrida de rua são: socialização; saúde; indicação médica; ansiedade; aparência; depressão. Maioral (2014), após um estudo sobre as principais pesquisas realizadas com corredores de rua no Brasil, afirma que o principal motivo para a prática da modalidade é a saúde. O quadro 2 retrata os principais resultados dessas pesquisas levantadas por Maioral (2014) a respeito das motivações encontradas em estudo com corredores de rua no Brasil. Como pode ser observado, o domínio ${ }^{5}$ saúde apareceu como principal fator em quase todos os estudos (Quadro 2).

\begin{tabular}{|c|c|c|c|}
\hline Cidade & Tipo & Principal Fator & Autor \\
\hline Porto Alegre & $\begin{array}{c}\text { Motivos de prática da } \\
\text { atividade } \\
\text { supervisionada }\end{array}$ & $\begin{array}{l}\text { 1. Saúde } \\
\text { 2. Prática ao ar livre } \\
\text { 3. Controle de ansiedade }\end{array}$ & $\begin{array}{c}\text { Truccolo, Maduro e Feijó } \\
2008\end{array}$ \\
\hline Porto Alegre & $\begin{array}{l}\text { Motivos de adesão à } \\
\text { prática de corrida de } \\
\text { rua }\end{array}$ & $\begin{array}{c}\text { 1. Saúde } \\
\text { 2. Prazer } \\
\text { 3. Controle de Estresse }\end{array}$ & Gonçalves, 2011 \\
\hline Fortaleza & $\begin{array}{c}\text { Motivos de adesão à } \\
\text { prática de corrida de } \\
\text { rua } \\
\end{array}$ & $\begin{array}{l}\text { 1. Saúde } \\
\text { 2. Lazer } \\
\text { 3. Auto-estima }\end{array}$ & Ribeiro e Costa, 2009 \\
\hline Sergipe & $\begin{array}{c}\text { Motivos de adesão a } \\
\text { eventos de corrida de } \\
\text { rua }\end{array}$ & $\begin{array}{l}\text { 1. Saúde } \\
\text { 2. Diversão } \\
\text { 3. Superação }\end{array}$ & Mendonça e Brito, 2012 \\
\hline São Paulo & $\begin{array}{l}\text { Motivos de adesão à } \\
\text { prática de corrida de } \\
\text { rua }\end{array}$ & $\begin{array}{c}\text { 1. Saúde } \\
\text { 2. Lazer } \\
\text { 3. Perda de Peso }\end{array}$ & Palhares et al, 2013 \\
\hline São Paulo & $\begin{array}{l}\text { Motivos de adesão à } \\
\text { prática de corrida de } \\
\text { rua em grupo }\end{array}$ & $\begin{array}{l}\text { Conveniência e praticidade; } \\
\text { ampliar o circulo de } \\
\text { relacionamento social; vontade } \\
\text { de serem percebidos como } \\
\text { pessoas saudáveis e } \\
\text { disciplinadas. }\end{array}$ & $\begin{array}{c}\text { Casadio, Oliveira e } \\
\text { Coelho, } 2010\end{array}$ \\
\hline Goiânia & $\begin{array}{l}\text { Motivos de adesão à } \\
\text { prática de corrida de } \\
\text { rua }\end{array}$ & $\begin{array}{l}\text { 1. Saúde } \\
\text { 2. Emagrecimento }\end{array}$ & $\begin{array}{l}\text { Carvalho, Guimarães e } \\
\text { Schmidt (2013) }\end{array}$ \\
\hline Curitiba & $\begin{array}{l}\text { Motivos de adesão à } \\
\text { prática de corrida de } \\
\text { rua } \\
\end{array}$ & 1. Saúde & Mileo e Scheid, 2012 \\
\hline Porto Velho & $\begin{array}{c}\text { Motivos de adesão a } \\
\text { eventos de corrida de } \\
\text { rua }\end{array}$ & $\begin{array}{l}\text { 1. Saúde } \\
\text { 2. Diversão } \\
\text { 3. Melhorar condição fisica }\end{array}$ & De Araujo, 2009 \\
\hline
\end{tabular}

Quadro 2 - Pesquisas realizadas com as motivações de adesão à prática de Corrida de Rua no Brasil - Maioral (2014) Fonte: Maioral (2014) 
Como é possível perceber, a motivação para a prática de corrida de rua pode ser avaliada por vários aspectos (Scalco, 2010). No caso deste estudo, verificaremos a motivação para a participação de eventos de corrida de rua. Para Funk (2008) o passo inicial para o entendimento do comportamento do consumidor esportivo deve ser a elaboração de um instrumento de pesquisa válido. Wann e Branscombe (1993) desenvolveram a Sport Fan Motivation Scale 6 (SFMS). Kahle, Kambara e Rose (1996) desenvolveram uma escala para medir a motivação dos espectadores nos eventos de futebol americano universitário. Os autores identificaram que os fãs eram motivados, principalmente, pelo desejo de participar de uma experiência única e de pertencer a um grupo específico. Posteriormente, Milne e Mc Donald (1999) utilizaram um instrumento que tentava responder questões relacionadas ao comportamento do espectador e do participante por meio de 12 constructos: assumir risco, redução do stress, agressividade, afiliação, facilitação social, autoestima, competição, realização, domínio de habilidades, estética, desenvolvimento de valor e auto- realização. Nesses trabalhos citados anteriormente é interessante notar que existem cinco fatores em comum, que são: socialização, performance, excitação, estima e diversão. Esses fatores serviram como base para Funk (2003) propor seu instrumento, denominado de SPEED. O instrumento foi utilizado para identificar os motivos de adesão dos consumidores nos jogos de futebol australiano. O questionário SPEED é a abreviação de: socialization, performance, excitement, esteem, diversion ${ }^{7}$.

Posteriormente, Jung-Hwan (2012) propôs um novo instrumento. Nesse instrumento, foram combinados os questionários SPEED, desenvolvido por Funk (2003), e o MSSC - Motivation Scale of Sport Consumption ${ }^{8}$, proposto por Trail e James (2001). Em seu trabalho, Jung-Hwan (2012) identificou as principais motivações que levam os jogadores de golfe a participarem de eventos da modalidade. Esse mesmo questionário híbrido foi utilizado por Maioral (2014) em sua dissertação de mestrado, na qual avaliou as motivações dos corredores que levam os participantes a escolherem eventos de corrida de rua. $\mathrm{O}$ objetivo desse questionário é identificar o principal motivo que faz com que os corredores participem de eventos de corrida de rua. Como o objetivo desse trabalho é identificar a motivação de consumidores/corredores em eventos esportivos, no caso específico a corrida

\footnotetext{
${ }^{6}$ Escala de Motivação dos Fãs do Esporte.

${ }^{7}$ Socialização, desempenho, excitação, estima e diversão.

${ }^{8}$ Escala de Motivação do Consumidor do Esporte
}

de rua, optou-se pelo questionário desenvolvido por Jung-Hwan (2012), pois, esse teria condição de fornecer as informações necessárias para o presente trabalho. No caso específico deste artigo, o evento escolhido para a aplicação do questionário e a coleta de dados foi a Maratona de São Paulo 2015, realizada dia 17 de maio, na capital paulista.

O evento Maratona de São Paulo foi escolhido para esta pesquisa porque engloba várias provas dentro de um único evento: caminhada de 3 $\mathrm{km}$, corridas de 10 e $24 \mathrm{~km}$ e a maratona de $42 \mathrm{~km}$. Além disso, o evento é um dos principais da modalidade no país, transmitido ao vivo pela Rede Globo de televisão, e que contou, em sua edição 2015, com a presença de 19 mil atletas, entre as quatro provas oferecidas (Globoesporte.com, 2015).

\section{MÉTODOS}

O estudo em questão é caracterizado como descritivo, que, segundo Gil (2008), tem como objetivo descrever algum fenômeno ou característica de determinada população, no caso, o comportamento dos corredores da Maratona de São Paulo. Uma característica importante desse tipo de pesquisa é a utilização de questionário como instrumento de coleta de dados (Vergara, 2004).

$\mathrm{O}$ universo da pesquisa foi composto por corredores devidamente inscritos no evento Maratona de São Paulo 2015. Dentro desse grupo, a amostra foi composta por 243 corredores, inscritos em todas as quatro provas do evento: caminhada de $3 \mathrm{Km}$, corridas de $10 \mathrm{~km}$ e $24 \mathrm{~km}$ e a maratona de $42 \mathrm{~km}$. A opção por incluir os participantes da caminhada de $3 \mathrm{Km}$ se deve pelo fato desse público também estar participando do evento em sua plenitude, e ser um público-alvo potencial para as produtoras de eventos de corrida de rua.

A coleta de dados foi realizada durante a "retirada do Kit" do evento. O momento "retirada do kit" foi escolhido em razão da disponibilidade dos corredores, durante esse período, para responder o questionário com mais tempo e maior tranquilidade, sem a pressão de se concentrar para a corrida no dia da prova. Com isso, acreditamos ter excluído das respostas fatores emocionais criados no momento do evento.

Antes da aplicação do questionário no evento, um pré-teste foi realizado no Campus da Cidade Universitária, local onde se localiza a Universidade de São Paulo (USP), a fim de verificar a compreensão dos respondentes e a validade do instrumento de coleta de dados. Esse pré-teste serviu de base para a construção do questionário final. 
No instrumento aplicado, foram apresentadas 27 afirmações sobre motivações para eventos de corrida de rua, para as quais os participantes responderam em uma escala de Likert de 1 (Discordo totalmente) a 5 (Concordo totalmente), o grau de concordância com cada uma delas. Cada três questões do questionário correspondiam a uma dimensão de motivação para participação no evento, somando assim nove dimensões: socialização, performance artística, estima, excitamento, distração, negócios, competição, condicionamento físico e domínio de habilidades. As questões foram distribuídas em ordem aleatória, de forma a não existir nenhuma questão da mesma dimensão em sequência, agrupada.

Após a verificação das respostas, entre os excluídos 6 questionários que não apresentavam pelo menos $70 \%$ das questões respondidas. Ao final, obtivemos uma amostra de 243 corredores. Para análise dos dados em todas as 27 perguntas, utilizou-se, como medida central, a média aritmética, e, como medida de dispersão, o desvio padrão. Posteriormente, para cálculo de cada uma das nove dimensões também foi utilizado a média aritmética.

\section{RESULTADOS}

Quando perguntados sobre a motivação para escolher o evento Maratona de São Paulo, podemos observar, no gráfico 1 , as médias de cada um dos nove domínios do questionário. inscritos na Maratona de São Paulo, foram

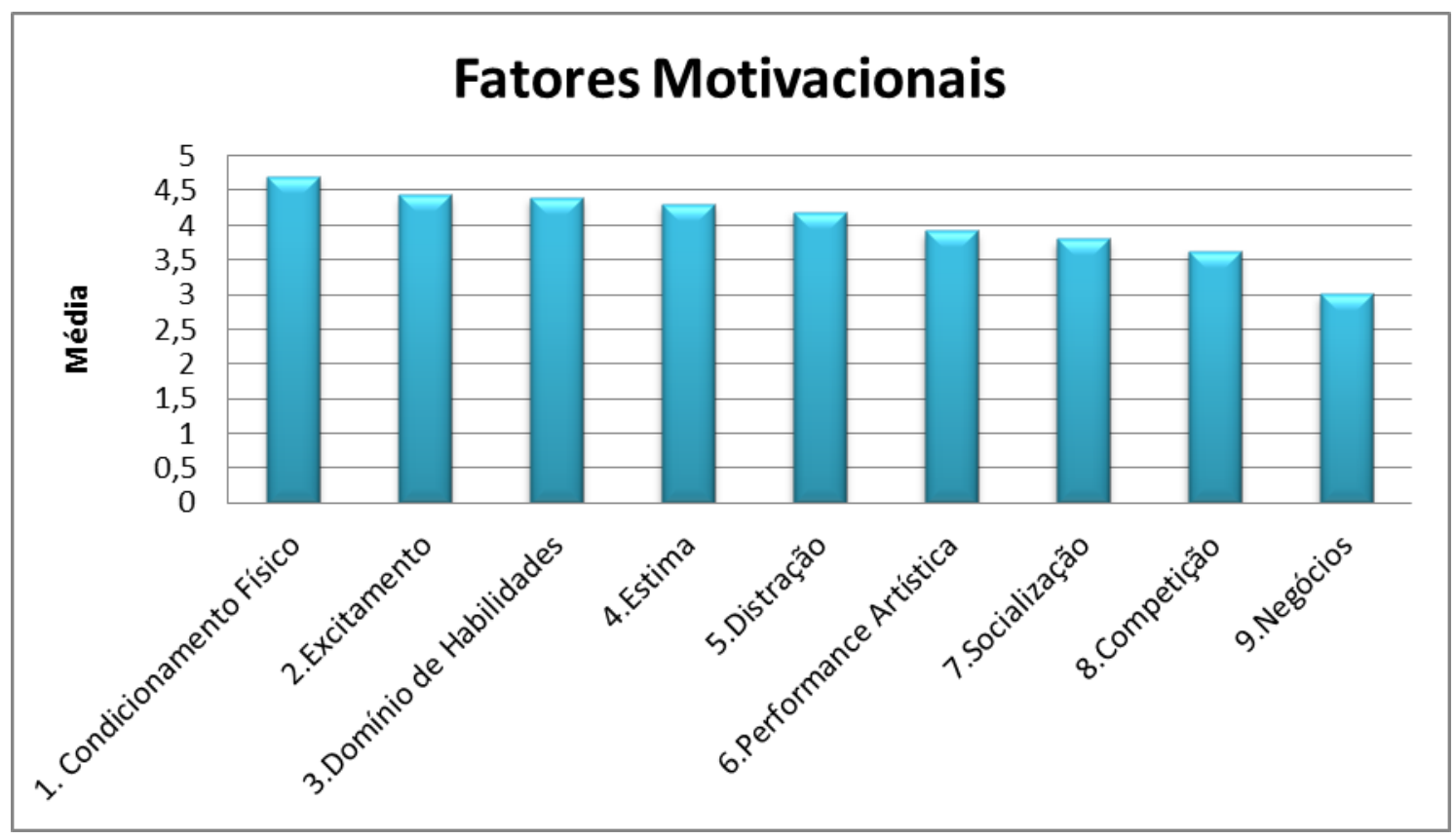

Gráfico 1 - Fatores que motivam os consumidores a participarem de um evento de corrida de rua Fonte: Próprios Autores

A dimensão que mais motiva os participantes é o condicionamento físico $(4,71)$, seguido pelo excitamento $(4,44)$ e o domínio de habilidades $(4,40)$. A dimensão competição aparece na oitava posição $(3,63)$. Negócios $(3,01)$ foi avaliada como a dimensão que menos motiva os participantes a escolher o evento corrida de rua.

Entre as 27 afirmações oferecidas aos respondentes, a que apareceu com a maior média de avaliação $(4,73)$ foi "eventos de corrida pedestre me ajudam a permanecer fisicamente ativo". Esse item pertence à dimensão condicionamento físico, seguido por "eu me sinto bem depois de praticar eventos de corrida pedestre", também ligado à mesma dimensão.
Em contrapartida, as afirmações com menor grau de concordância nas respostas, com médias 2,87 e 2,95, respectivamente, foram: “eventos de corrida pedestre me dão a chance de ter um relacionamento social com parceiros de negócios" e "eventos de corrida pedestre me ajudam a desenvolver conexões pessoais para meu negócio ou trabalho", ambas ligadas à dimensão negócios. As afirmações e seus domínios podem ser visualizados de forma mais clara na Tabela 1 , onde podemos observar a média aritmética e o desvio padrão de cada afirmação e à qual domínio a assertiva pertence. 
Tabela 1 - Média e desvio padrão das afirmações relacionadas aos nove domínios de motivação do consumidor

\begin{tabular}{|c|c|c|c|}
\hline Afirmações & Domínio & Média & $\begin{array}{l}\text { Desvio } \\
\text { Padrão }\end{array}$ \\
\hline $\begin{array}{l}\text { Eu gosto dos aspectos competitivos dos eventos de } \\
\text { corrida pedestre }\end{array}$ & Competição & 3,84 & 0,98 \\
\hline $\begin{array}{l}\text { Eu gosto do sentimento de ganhar de determinado } \\
\text { indivíduo em eventos de corrida pedestre }\end{array}$ & Competição & 3,06 & 1,35 \\
\hline $\begin{array}{l}\text { Eventos de corrida de rua me dão a oportunidade de } \\
\text { desenvolver meu espírito competitivo }\end{array}$ & Competição & 3,98 & 1,06 \\
\hline $\begin{array}{l}\text { Eventos de corrida pedestre me ajudam a permanecer } \\
\text { fisicamente ativo }\end{array}$ & $\begin{array}{l}\text { Condicionamento } \\
\text { Físico }\end{array}$ & 4,73 & 0,71 \\
\hline $\begin{array}{l}\text { Participar de eventos pedestres ajuda a me sentir } \\
\text { saudável }\end{array}$ & $\begin{array}{l}\text { Condicionamento } \\
\text { Físico }\end{array}$ & 4,68 & 0,62 \\
\hline $\begin{array}{l}\text { Eu me sinto bem depois de praticar eventos de corrida } \\
\text { pedestre }\end{array}$ & $\begin{array}{l}\text { Condicionamento } \\
\text { Físico }\end{array}$ & 4,72 & 0,59 \\
\hline $\begin{array}{l}\text { Eventos de corrida pedestre me ajudam a diminuir a } \\
\text { tensão e ansiedade }\end{array}$ & Distração & 4,39 & 0,8 \\
\hline $\begin{array}{l}\text { Eventos de corrida pedestre dão a oportunidade de dar } \\
\text { uma pausa no meu dia }\end{array}$ & Distração & 3,82 & 1,13 \\
\hline $\begin{array}{l}\text { Eventos de corrida pedestre me ajudam a aliviar meu } \\
\text { stress mental }\end{array}$ & Distração & 4,38 & 0,83 \\
\hline $\begin{array}{l}\text { Eu quero alcançar um objetivo nos eventos de corrida } \\
\text { pedestre }\end{array}$ & $\begin{array}{l}\text { Domínio de } \\
\text { Habilidades }\end{array}$ & 4,39 & 0,89 \\
\hline $\begin{array}{l}\text { Gosto da sensação de atingir melhores resultados que o } \\
\text { habitual em eventos de corrida pedestre }\end{array}$ & $\begin{array}{l}\text { Domínio de } \\
\text { Habilidades }\end{array}$ & 4,45 & 0,85 \\
\hline $\begin{array}{l}\text { Eu gosto da sensação de melhorar minhas habilidades em } \\
\text { eventos de corrida pedestre }\end{array}$ & $\begin{array}{l}\text { Domínio de } \\
\text { Habilidades }\end{array}$ & 4,48 & 0,81 \\
\hline $\begin{array}{l}\text { Participar de eventos de corrida pedestre me traz um } \\
\text { sentimento de autoconfiança }\end{array}$ & Estima & 4,58 & 0,69 \\
\hline $\begin{array}{l}\text { Eventos de corrida pedestre me fazem sentir confiante } \\
\text { sobre minhas habilidades }\end{array}$ & Estima & 4,25 & 0,91 \\
\hline $\begin{array}{l}\text { Eventos de corrida pedestre ajudam a desenvolver meu } \\
\text { potencial }\end{array}$ & Estima & 4,31 & 0,82 \\
\hline $\begin{array}{l}\text { Sinto uma grande alegria ao participar de eventos de } \\
\text { corrida pedestre }\end{array}$ & Excitamento & 4,71 & 0,63 \\
\hline Acho os eventos de corrida pedestre emocionantes & Excitamento & 4,3 & 0,94 \\
\hline Eventos de corrida pedestre são divertidos & Excitamento & 4,31 & 0,88 \\
\hline $\begin{array}{l}\text { Eventos de corrida pedestre me ajudam com meu } \\
\text { negócio e/ou carreira profissional }\end{array}$ & Negócio & 3,21 & 1,27 \\
\hline $\begin{array}{l}\text { Eventos de corrida pedestre me dão a chance de ter um } \\
\text { relacionamento social com parceiros de negócios }\end{array}$ & Negócio & 2,87 & 1,29 \\
\hline $\begin{array}{l}\text { Eventos de corrida pedestre me ajudam a desenvolver } \\
\text { conexões pessoais para meu negócio ou trabalho }\end{array}$ & Negócio & 2,95 & 1,31 \\
\hline Eu acho a corrida pedestre um esporte bonito & $\begin{array}{l}\text { Performance } \\
\text { Artística }\end{array}$ & 4,57 & 0,76 \\
\hline Eu gosto da elegância associada à corrida pedestre & $\begin{array}{l}\text { Performance } \\
\text { Artística }\end{array}$ & 3,52 & 1,08 \\
\hline $\begin{array}{l}\text { Eu gosto da graciosidade (beleza) associada à corrida } \\
\text { pedestre }\end{array}$ & $\begin{array}{l}\text { Performance } \\
\text { Artística }\end{array}$ & 3,68 & 1,08 \\
\hline $\begin{array}{l}\text { Eventos de corrida pedestre me dão a oportunidade de } \\
\text { conhecer novas pessoas }\end{array}$ & Socialização & 4,18 & 1,02 \\
\hline $\begin{array}{l}\text { Eventos de corrida pedestre me dão a oportunidade de } \\
\text { passar o tempo com meus amigos }\end{array}$ & Socialização & 3,86 & 1,14 \\
\hline $\begin{array}{l}\text { Eventos de corrida pedestre me dão a oportunidade de } \\
\text { socializar por meio de redes sociais }\end{array}$ & Socialização & 3,35 & 1,32 \\
\hline
\end{tabular}

Fonte: Próprios Autores 
Maioral (2014), em seu estudo, aplicando o mesmo questionário em corredores de todo o Brasil, encontrou valores semelhantes: o principal motivo para a prática da corrida de rua era o condicionamento físico $(4,5)$, seguido por domínio de habilidades $(4,3)$ e excitamento $(4,1)$. Os resultados desse trabalho coincidem com aqueles obtidos por Maioral (2014).

Truccolo, Maduro e Feijó (2008) em seu estudo sobre fatores motivacionais em adesão a grupos de corrida de rua, encontaram que $29 \%$ das mulheres são motivadas pelo fator saúde. No caso dos homens, esse número cai para $20 \%$. Para ambos os sexos, o fator saúde aparece como maior motivador para a participação em eventos dessa natureza. Todos esses dados corroboram com Palhares, Bennet, Mazzei \& Bastos (2012) que também identificaram o domínio saúde como principal motivo para a participação de pessoas em eventos de corrida de rua.

$\mathrm{Na}$ mesma linha, Casadio, Oliveira e Coelho (2010) apuraram que o principal motivo para a prática da corrida de rua eram os discursos de superação, de fácil acesso ao esporte e de diversão. Nesse mesmo sentido, Nunomura (1998), em seu estudo sobre as razões dos indivíduos permanecerem fisicamente ativos, encontrou $o$ condicionamento físico e a saúde como sendo os principais motivos. Todas essas pesquisas, anteriormente realizadas em diversos contextos, são confirmadas pelo nosso estudo. $\mathrm{O}$ condicionamento físico permanece como o principal motivo para a adesão de participantes ao evento corrida de rua.

Quando dividimos os participantes em grupos de acordo com a faixa etária e seguindo a divisão feita pela Maratona de São Paulo entre suas categorias, observamos alguns pontos relevantes. $\mathrm{O}$ primeiro ponto a ser destacado é que, em todas as categorias, a dimensão "condicionamento físico" aparece como principal motivo para participação no evento. Porém, na categoria que compreende a faixa etária de 20 a 24 anos, a dimensão "performance artística" aparece entre os três primeiros elementos de motivação, com média 4,66 .

Outro fato interessante pode ser observado nas categorias de 40 a 44 anos, 50 a 54 anos e 55 a 59 anos. Nessas categorias, o domínio "estima" aparece entre os três principais fatores de motivação, com médias, respectivamente, de 4,36, 4,51 e 4,56, mostrando que, com o aumento da idade, a corrida de rua se torna um aliado para a maior valorização da autoestima do indivíduo.

Para os corredores acima de 69 anos, o domínio "distração" aparece entre os três primeiros motivos para a participação em um evento de corrida de rua. Esse elemento evidencia um dos fatores pelos quais muitos indivíduos procuram o esporte hoje: aliviar a tensão, a ansiedade e o estresse do dia-a-dia, além de proporcionar momentos de lazer e de prática corporal saudável. Esse domínio, ao qual chamamos de "distração", Palhares et al. (2012) inseriram dentro do termo "saúde".

Dentro desse mesmo contexto, Truccolo et al. (2008) encontraram que a principal razão para os homens aderirem às corridas de rua com orientação profissional é a diminuição da ansiedade. Freitas, Santiago, Viana, Leão \& Freyre (2007) em um estudo com população idosa, apontaram que os motivos prioritários para a prática de exercício físico é a melhora da saúde e a redução do estresse.

Outra discussão a ser feita neste artigo é sobre o perfil dos corredores deste estudo e seu grau de envolvimento com a corrida de rua. Para isso, as questões como idade, sexo, escolaridade e renda foram classificadas como dados sóciodemográficos. Para identificar o grau de envolvimento com a corrida de rua, o instrumento continha três perguntas relacionadas ao tempo médio semanal dedicado a treinos da modalidade, número de provas já participadas e tempo de prática (em anos).

Quanto ao sexo dos participantes, a grande maioria foi do sexo masculino (78\%). Os resultados obtidos corroboram com o estudo de Mendonça e Brito (2012) que encontraram dados semelhantes, com 72,2 \% do público corredor masculino. O estudo dos autores tinha como objetivo analisar o perfil sócio- demográfico e de características associadas ao treinamento de corredores de rua, em Sergipe. Isso evidencia que, apesar do segundo running boom, na década de 1990, indicar que a participação feminina aumentou, ainda temos os participantes do sexo masculino como a grande maioria em eventos de corrida de rua.

Quanto à idade dos corredores da amostra, os participantes tinham uma média de 43,8 anos. Palhares et al. (2012) em seu estudo sobre o perfil e preferências dos corredores, encontraram que 24 dos 89 corredores entrevistados tinham entre 45 e 59 anos.

Em relação ao nível de escolaridade dos corredores, do total de 222 respondentes, 92 dos respondentes tinham Ensino Superior completo, 41 tinham Especialização, 35 tinham Ensino Médio, 23 tinham Mestrado ou Doutorado, 17 tinham Ensino Tecnológico, 12 tinham Ensino Fundamental e 2 não responderam a essa questão. Em contrapartida, Mendonça et al. (2012) em seu estudo, encontraram que a grande maioria dos corredores tinha como maior grau de escolaridade o Ensino Médio (37,2 $\%)$. 
Com relação à renda mensal, foram encontrados os seguintes valores: $39 \%$ dos participantes possuem renda entre $\mathrm{R} \$ 2.900,00$ a $\mathrm{R} \$$ $7.249,00 ; 22 \%$ possuem renda entre de $\mathrm{R} \$ 7.250,00$ e R \$ $14.4449,00 ; 16 \%$, até R\$ $1.449,00 ; 15 \%$ entre $\mathrm{R} \$ 1.450,00$ a $\mathrm{R} \$ 2.889,00$ e $8 \%$ têm renda acima de $\mathrm{R} \$ 14.500,00$.

Quanto ao número de provas de corrida de rua que já haviam participado, 206 dos 243 corredores já haviam estado presente em mais de 10 provas; 28 entrevistados estiveram presentes entre 5 e 10 provas; outros 28 entre 1 e 5 provas, e apenas 4 estavam participando de uma corrida de rua pela primeira vez.

Sobre as horas dedicadas aos treinos para corrida de rua, semanalmente, $38 \%$ afirmaram treinar entre 3 e 6 horas; $33 \%$ entre 6 e 10 horas; $15 \%$ mais do que 10 horas; $4 \%$ treinam menos de 1 hora por semana e $10 \%$ não responderam. Podemos constatar que quase a metade dos corredores (48\%) dedica, no mínimo, 6 horas por semana em treinos para participar de eventos dessa natureza, mostrando que, mesmo sendo um esporte com apelo de participação, existe a dedicação dos praticantes em treinos semanais da modalidade.

Por fim, para caracterizar o envolvimento com a corrida de rua, foi questionado o tempo de prática da modalidade (em anos) pelos corredores. O resultado ficou assim: $35 \%$ dos corredores já praticam a corrida de rua há mais de 10 anos; $30 \%$ começaram a praticar entre 2 a 5 anos atrás; $21 \%$ de 5 a 10 anos, $9 \%$ de 1 a 2 anos, e $5 \%$ de seis meses a 1 ano. Todos esses dados acerca do perfil dos participantes desse estudo pode ser melhor visualizado no quadro 3 .

\begin{tabular}{|c|c|c|}
\hline Sexo & $\begin{array}{l}\text { Masculino } 78 \% \\
\text { Feminino 22\% }\end{array}$ & \\
\hline Idade & Média 43, 8 anos & \\
\hline \multirow{7}{*}{ Nível de Escolaridade } & Ensino Fundamental & $4 \%$ \\
\hline & Ensino Médio & $16 \%$ \\
\hline & Ensino Superior & $45 \%$ \\
\hline & Ensino Tecnológico & $6 \%$ \\
\hline & Especialização & $19 \%$ \\
\hline & Mestrado ou Doutoramento & $9 \%$ \\
\hline & Não responderam & $1 \%$ \\
\hline \multirow{5}{*}{ Renda Mensal } & Até 1449,00 & $16 \%$ \\
\hline & De 1450 a 2899 & $15 \%$ \\
\hline & 2900 a 7249 & $39 \%$ \\
\hline & 7250 a 14449 & $22 \%$ \\
\hline & 14500 ou mais & $8 \%$ \\
\hline \multirow{4}{*}{ Número de Provas já praticadas } & 1 prova & $2 \%$ \\
\hline & 1 a 5 provas & $6 \%$ \\
\hline & 5 a 10 provas & $6 \%$ \\
\hline & mais que 10 provas & $86 \%$ \\
\hline \multirow{5}{*}{$\begin{array}{l}\text { Horas dedicadas aos treinos de } \\
\text { corrida de rua }\end{array}$} & 0 a 1 hora & $4 \%$ \\
\hline & 3 a 6 horas & $38 \%$ \\
\hline & 6 a 10 horas & $33 \%$ \\
\hline & mais que 10 horas & $15 \%$ \\
\hline & não responderam & $10 \%$ \\
\hline
\end{tabular}




\begin{tabular}{|c|lr|}
\hline \multirow{3}{*}{ Tempo de prática da modalidade } & 6 meses a 1 ano & $5 \%$ \\
(em anos) & 1 a 2 anos & $9 \%$ \\
& 2 a 5 anos & $30 \%$ \\
& 5 a 10 anos & $21 \%$ \\
& acima 10 anos & $35 \%$ \\
\hline
\end{tabular}

Quadro 3 - Resumo do perfil dos participantes do estudo Fonte: Próprios autores

\section{CONCLUSÃo}

O presente estudo apresentou como seu objetivo central identificar os principais motivos que levam os corredores a participarem de um evento de corrida de rua na cidade de São Paulo. No caso deste estudo, os corredores que participaram da Maratona de São Paulo 2015 compuseram o universo de coleta de dados. O principal motivo identificado pelos 243 componentes da amostra foi o condicionamento físico. Isso pode ser explicado pelo alto grau de envolvimento dos respondentes com a corrida de rua, pois, como percebemos, a maioria dos participantes entrevistados treina a mais de cinco anos e no mínimo 6 horas por semana. Com isso, esses indivíduos conseguem usufruir dos benefícios que o treinamento de corrida de rua oferece em longo prazo e um deles é o condicionamento físico, que se torna assim o principal motivo para continuarem praticando e, consequentemente, participando de eventos de corrida de rua. São indivíduos que "investem" tempo e recursos financeiros na corrida de rua como forma de melhoria da própria saúde e qualidade de vida.

Outro aspecto relevante apontado na pesquisa é a dimensão "excitamento", que aparece como o segundo principal motivo para adesão à participação em eventos dessa natureza. Isso reforça o pensamento contemporâneo de que os eventos esportivos "dialogam" com o entretenimento. $\mathrm{O}$ individuo paga a inscrição para praticar esporte e, ao mesmo tempo, entreter-se. Com isso, os eventos de corrida de rua aparecem como um local interessante para os indivíduos praticarem o que treinaram durante um determinado período. Além disso, os eventos propiciam momentos únicos, experiências marcantes, e os indivíduos reforçam a ideia de continuar praticando os treinos para participarem de outras experiências ou outros eventos. Esse é um convite para tais indivíduos se divertirem e sentirem toda a emoção dessa experiência única novamente. $\mathrm{O}$ evento corrida de rua assume, aqui, nessa dimensão, o caráter de produto de consumo do esporte, com o participante ocupando o papel maior de "consumidor" desse produto esportivo em detrimento de seu papel menor, enquanto corredor ou atleta. Resumindo, temos um ciclo onde o indivíduo treina para participar de uma corrida de rua e, após sair de um desses eventos, sente-se mais motivado a treinar para um próximo evento. Nesse tempo, entre uma corrida e outra, o indivíduo começa a perceber os benefícios físicos de uma prática regular desse tipo de atividade, fazendo com que isso se torne um estilo de vida daquela pessoa.

Por outro lado, os dados obtidos podem ser interessantes aos organizadores de eventos de corrida de rua, pois, como percebemos, os motivos podem se diferenciar, dependendo da faixa etária dos participantes. Portanto, cabe aos organizadores perceberem esse consumidor e produzirem eventos que possam proporcionar satisfação a todos os envolvidos.

Esse estudo pode auxiliar, também, no entendimento de um componente específico do comportamento do consumidor: a motivação. Contudo, como sabemos, o comportamento do consumidor é muito mais complexo e amplo do que os aspectos relacionados à motivação. $\mathrm{O}$ processo de tomada de decisão dos participantes de eventos esportivos não deve considerar apenas a motivação desses consumidores e, sim, vários outros aspectos que comtemplem os fatores que interferem na participação dentro do mercado de corrida de rua. É essa a principal limitação deste artigo e um convite a que outros pesquisadores procurem contemplar elementos distintos da motivação para um entendimento maior do processo de tomada de decisão em corridas de rua.

\section{REFERÊNCIAS}

Campos, T. M.; Moraes, M. B.; Lima, E. (2014). Rede de relação e empreendedorismo na realização de corridas de rua. Encontro de estudos em empreendedorismo e gestão de pequenas empresas, VIII., 2014, Goiânia. Anais VIII EGEPE. Goiânia.

Casadio, P; Oliveira, T; Coelho, E. (2010). Motivos para a prática da corrida de rua orientada e não orientada por profissionais de educação física. Coleção Pesquisa em Educação Física- Vol.9, n.6. 
Dallari, M. M. (2009). Corrida de rua: um fenômeno sociocultural contemporâneo. São Paulo: USP, 2009. 130p. Tese (Doutorado em educação) Faculdade de educação, Universidade de São Paulo, São Paulo.

Diário Catarinense. (2013). Crescimento das corrida de rua no Brasil Disponível em: <http://wp.clicrbs.com.br/ivanahenn/2013/07/03/ocrescimento-das-corridas-de-rua-nobrasil/?topo $=67,2,18,,, 67>$. Recuperado em maio de 2015.

Deloitte (2011). Muito além do futebol: estudos sobre esportes no Brasil.

https://disciplinas.stoa.usp.br/pluginfile.../Pesquisa_ Esportes_Deloitte_2011.pdf?. Acesso em:10 de junho de 2015.

FPA- Federação Paulista de Atletismo (2016). Estatísticas Corrida de Rua 2015. <http://www.atletismofpa.org.br/Corrida-deRua/Estat\%C3\%ADstica-2014> . Acesso em: 14 de junho de 2016.

Freitas, C. M. S. M.; Santiago, M. S.; Viana, A. T.; Leão, A. C.; Freyre, C. (2007). Aspectos motivacionais que influenciam a adesão e manutenção de idosos a programas de exercícios físicos. Revista Brasileira de Cineantropometria e Desempenho Humano, Florianópolis, v.9, n.1, p.92100.

Funk, D. (2008). Consumer behaviour in sports and events: Marketing Action. Burlington: Elsevier.

Gil, A. C. (2008). Como elaborar projetos de pesquisa 4a ed. São Paulo: Atlas.

Globoesporte.com. (2015). Maratona de São Paulo, 2015.<http://globoesporte.globo.com/euatleta/corridas-e-eventos/maratona-de-sp/> . Acesso em: 12 de junho de 2015 .

Gomes, M. (2012). Divulgação da ciência do esporte - o caso especializado da mídia de corrida de rua. 2012. 162 f. Dissertação (Mestrado em Divulgação Científica e Cultural) - Instituto de Estudos da Linguagem e ao Laboratório de Estudos Avançados em Jornalismo, Universidade Estadual de Campinas, Campinas.

Hawkins, D. I.; Mothersbaugh, David L.; Best, Roger J. (2007). Comportamento do consumidor Construindo a estratégia de marketing. Rio de Janeiro: Elsevier.
Holbrook, M, B; Hirschman,E, C. (1982) The Experiential Aspects of Consumption: Consumer Fantasies, Feelings, and Fun. Journal of Consumer Research, v.9.

Jung-hwan, J. (2012). Participants' Psychological Connection to Recreational Sports: An Examination of the Psychological Continuum Model Framework. 2012. 144 f. Tese (Doutorado em Filosofia) -

University of Raleigh, Raleigh.

Kahle, L.R., Kambara, K.M., \& Rose, G. (1996). A functional model of fan attendance motivations for college football. Sport Marketing Quarterly, 5(4), 51-60.

Maioral, R, F. (2014). Identificação e avaliação dos atributos que influenciam a decisão de participação em eventos de corrida pedestre no Brasil.

Dissertação (Mestrado) - Universidade do Estado de Santa Catarina, Centro de Ciências da Administração e Sócioconômicas, Florianópolis.

Mendonça, M. O. A; Brito, C. J. (2012). A análise do perfil sociodemográfico e de características associadas a treinamento e competições de corredores de rua de Sergipe. Revista Mineira de Educação Física, Viçosa, Edição Especial, n. 1, p. 1749-1760.

Milne, G.R.; McDonald, M. A. (1999). Sport Marketing: Managing the Exchange Process. Sudbury: Jones and Bartlett Publishers.

Mullin, B. J.; Hardy, S.; Sutton, W. A. (2004). Marketing Esportivo. 2. ed. Porto Alegre: Bookman/Artemd.

Noakes, T. (1991). Lore of running. 3. ed. Champaign: Leisure Press.

Nunomura, M. (1998). Motivo de adesão à atividade física em função das variáveis idade, sexo, grau de instrução e tempo de permanência. Revista Brasileira de Atividade Física e Saúde, Londrina, v.3, n.3, p.45-58.

Oliveira, S. N. (2010). Lazer Sério e Envelhecimento: loucos por corrida. Dissertação (Mestrado em Educação) - Faculdade de Educação, Universidade Federal do Rio Grande do Sul. Porto Alegre.

Palhares, J. M; Bennet, M.; Mazzei, L. C.; Bastos, F. C. (2012). Perfil e preferências de praticantes de corrida de rua: um estudo preliminar. Revista Mineira de Educação Física, Viçosa, Edição Especial, n. 1, p. 1664-1673. 
Redden, J; Steiner, C. (2000) Fanatical Consumers: Toward a framework for research. Journal of Consumer Marketing, v. 17, n 4, p. 322-337.

Rocco Júnior, A. J. (2006). O Gol por um clique: uma incursão ao universo da cultura do torcedor de futebol no ciberespaço. $281 \mathrm{f}$. Tese (Doutorado em Comunicação e Semiótica) - Pontifícia

Universidade Católica de São Paulo, São Paulo.

Scalco, L. M. (2010). Por isso corro demais... Notas etnográficas de uma corredora iniciante. Revista Brasileira de Sociologia da Emoção, v. 9, n. 25, p. 312-355.

Stewart, B; Smith, A; Nicholson, M. (2003). Sport Consumer Typologies: A critical Review. Sports Marketing Quarterly. p.206-216.

Trail, G. T.; James, J. D. (2001). The motivation scale for sport consumption: Assessment of the scale's psychometric properties. Journal of Sport Behavior, [S.I.], v. 24, n. 1, p. 108-127.

Truccolo, A. B.; Maduro, P. A.; Feijó E. (2008). A. Fatores motivacionais a adesão a grupos de corrida. Revista Motriz, Rio Claro, v.14, n.2, p. 108-114.
Tubino, M. J. G. (2002). Dimensões sociais do esporte. 3. ed. São Paulo: Cortez.

Van Bottenburg, M.; Hover, P.; Scheerder, J. (2010). Don't miss the next boat. Chances and challenges of the second wave of running. New Studies in Athletics, v. 25, n. 3/4, p. 125-143.

Vergara, S. C. (2004). Projetos e relatórios de pesquisa em Administração. São Paulo: Atlas. Wann, D. L., \& Branscombe, N. R. (1993). Sports fans: Measuring degree of identification with the team. International Journal of Sport Psychology, 24, 1-17.

Webrun. (2002). Histórico da organização de corridas de rua no Brasil. Disponível em: <http://www.webrun.com.br/h/noticias/historicoda-organizacao-de-corridas-de-rua-no- brasil/158>. Acesso em: 10 de junho de 2015.

Weineck, J. (2003). Atividade física e esporte para $q u \hat{e}$ ? São Paulo: Manole. 